\title{
UNA ESPECIE NUEVA DE HIBISCUS (MALVACEAE) DEL ESTADO DE OAXACA
}

\author{
Paul A. Fryxell \\ U.S. Department of Agriculture, Agricultural Research Service \\ en cooperación con \\ Texas A\&M University, College Station, Texas 77843, E.E.U.U.
}

\begin{abstract}
RESUMEN
Se describe e ilustra una especie nueva, Hibiscus tenorii, del oeste del estado de Oaxaca. La planata es afín a un grupo de especies de Hibiscus del occidente y sur de México con corolas rojas tubulares y con los androceos y estilos muy exsertos.
\end{abstract}

\begin{abstract}
A new species from western Oaxaca, Hibiscus tenorii, is decribed and illustrated. It is related to a group of western and southern Mexican species of Hibiscus with red, tubular corollas and with androecium and styles prominently exserted.
\end{abstract}

Fryxell (1988) resumió la información sobre la morfología y distribución de las especies mexicanas de Hibiscus, incluyendo un grupo caracterizado por tener flores rojas con corolas tubulares y con androceos y estilos bien exsertos. Este grupo abarca $H$. acapulcensis Fryx., H. colimensis Fryx., H. kochii Fryx., H. nelsonii Rose \& Standl. ex Standl., H. peripteroides Fryx. y H. spiralis Cav. (Fryxell, 1988, fig. 50). Las especies del grupo se distribuyen mayormente en la vertiente pacífica de México, desde Jalisco hasta el Istmo de Tehuantepec (fig. 1). Entre especímenes recientemente colectados encontré otra especie del grupo, la cual se describe a continuación.

Hibiscus tenorii Fryxell, sp. nov.

Frutex 1-1.5 m altus, stellato-pubescens; foliis lanceolatis vel ovatis usque $4.5 \mathrm{~cm}$ longis; pedicellis solitariis in axillis foliorum 6-8 $\mathrm{mm}$ longis dense pubescentibus; bracteolis involucellorum 7-10 mm longis $1-1.5 \mathrm{~mm}$ latis; calyce $10-12 \mathrm{~mm}$ longo dense pubescenti; petalis rubris $3 \mathrm{~cm}$ longis corollam tubularem formantibus; androecio exserto; stylis purpuratis androecium excedentibus, stigmatibus capitatis purpuratis $1 \mathrm{~mm}$ diametro. Fructus ignotus.

Arbusto de 1-1.5 m de altura, los tallos jóvenes con pelos estrellados adpresos, los pelos a veces densos y dispuestos en líneas longitudinales. Láminas de las hojas lanceoladas $u$ ovadas, 2-4.5 cm de longitud, $1-2 \mathrm{~cm}$ de ancho, truncadas en la base, aserradas, agudas o levemente acuminadas, palmati-5-nervadas, más o menos pubescentes, en el envés con pelos estrellados, en el haz con pelos con frecuencia bifurcados; nectario foliar en la base del nervio principal; pecíolo hasta de $6 \mathrm{~mm}$ de largo, con pelos estrellados; estípulas 4-5 mm de largo, erectas, subuladas, persistentes. Flores solitarias en las axilas de las hojas; pedicelos 6-8 $\mathrm{mm}$ 
Acta Botánica Mexicana (1989), 8:35-38

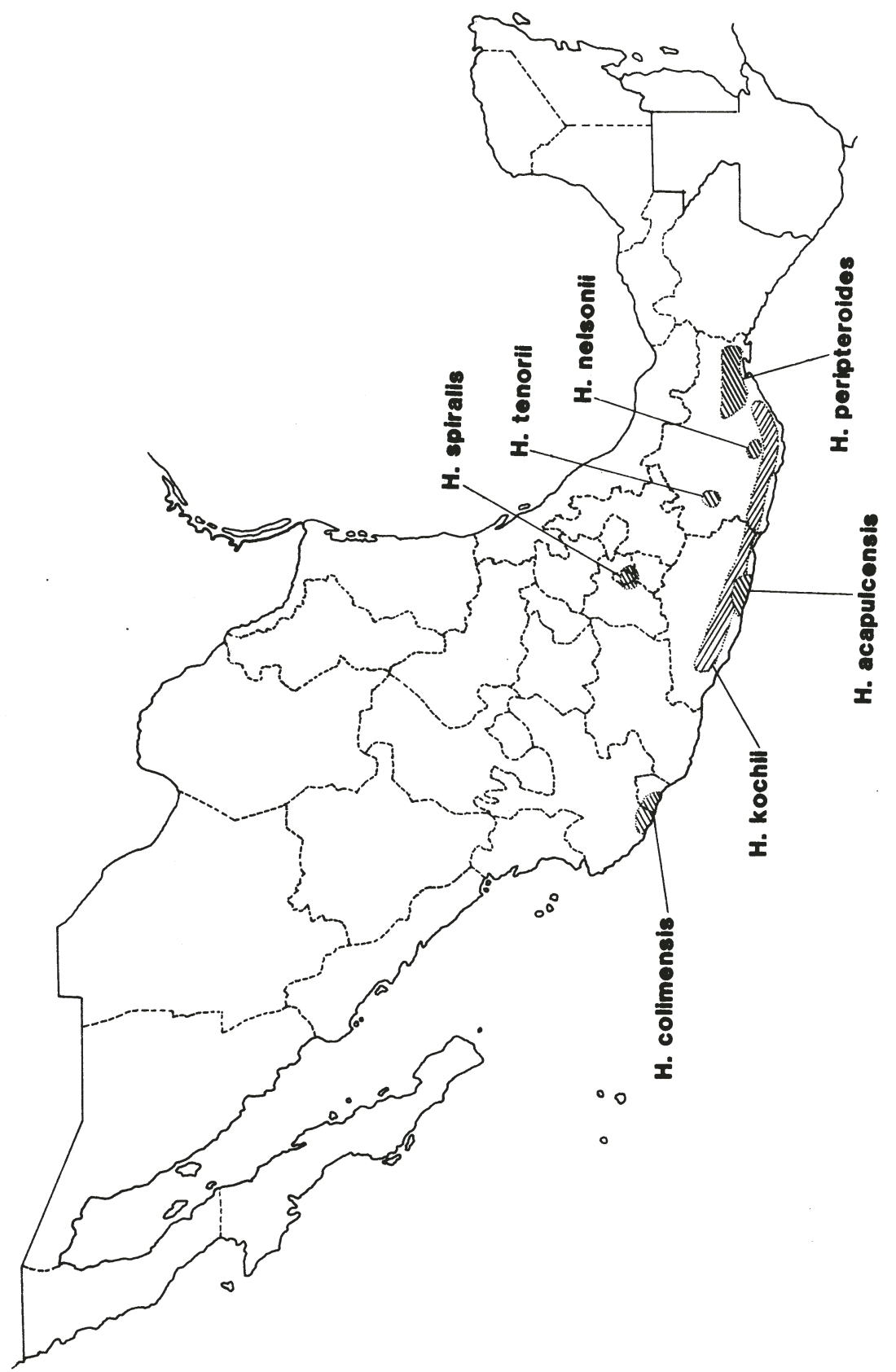

Fig. 1. Mapa de la distribución de las especies de Hibiscus con flores rojas y tubulares. 
de largo, densamente pubescentes, los pelos amarillentos, estrellados; bractéolas del calículo usualmente 9, casi libres, 7-10 mm de longitud, lanceoladas u oblanceoladas, 1-1.5 mm de ancho, ciliadas, los pelos 0.2-0.4 mm de longitud; cáliz 10-12 mm de longitud, tubular, 7-9 mm de diámetro, densamente pubescente, amarillento, los lóbulos aproximadamente $4 \mathrm{~mm}$ de largo, redondeado-agudos, a veces con pigmentación oscura en los ápices; pétalos $3 \mathrm{~cm}$ de longitud, distalmente rojos, formando un tubo estrechamente torcido, con pelos estrellados; androceo exserto, los filamentos más o menos $2 \mathrm{~mm}$ de longitud, los estambres rojizos, el polen amarillo; estilos 5, purpúreos, sobrepasando el androceo por 4-5 mm, los estigmas capitados, purpúreos, $1 \mathrm{~mm}$ de diámetro. Frutos desconocidos (Fig. 2).

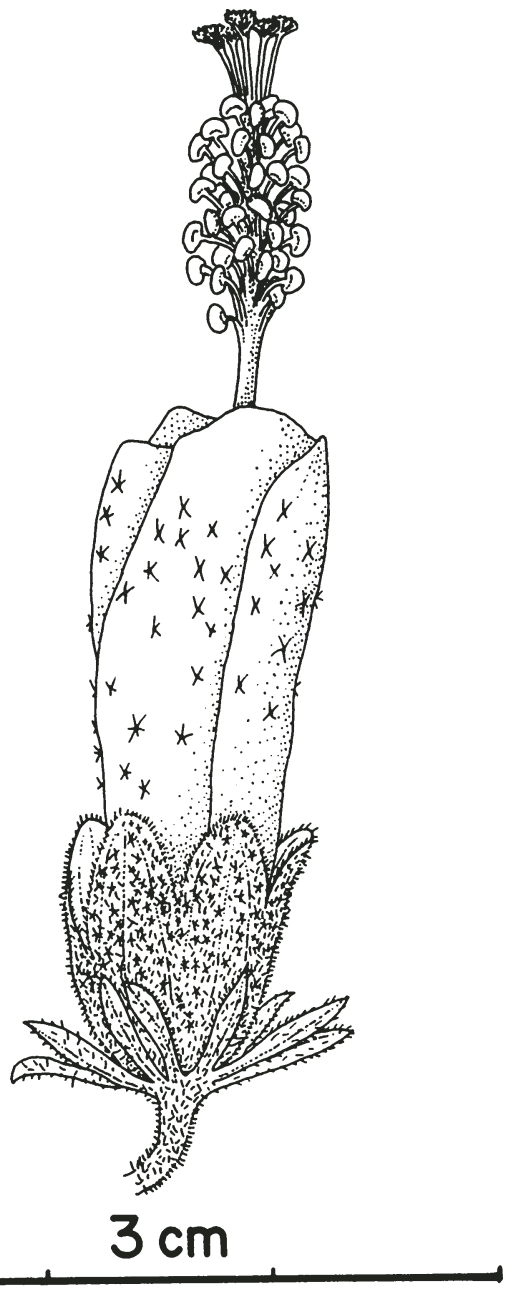

Fig. 2. Hibiscus tenorii. Flor. 
TIPO: México, Oaxaca. $14 \mathrm{~km}$ al S de San Marcos Arteaga, carretera Huajuapan de León-Juxtlahuaca, Distr. Juxtlahuaca, alt. $1780 \mathrm{~m}$; bosque de encino, suelo calizo con materia orgánica, 21 marzo 1983, Tenorio, Torres \& Romero 3620 (holotipo: MEXU; isotipos: MEXU, $\left.p^{*}\right)$.

Hibiscus tenorii se distingue de las demás especies del grupo por tener pétalos más grandes $(3 \mathrm{~cm})$ y pedicelos más breves. La especie más parecida es $H$. nelsonii, con la cual comparte el cáliz densamente pubescente. Hibiscus tenorii difiere de $H$. nelsonii, por tener bractéolas del calículo más angostas, pedicelos más breves, así como estigmas, hojas y pétalos más grandes.

Al presente la especie nueva se conoce solamente de la colección citada del oeste de Oaxaca. Conforme con las otras especies del grupo, $H$. tenoriiocupa una área restringida en la vertiente pacífica.

Es un placer dedicar esta especie hermosa al colector del tipo, Biól. Pedro Tenorio L.

\section{LITERATURA CITADA}

Fryxell, P. A. 1988. Malvaceae of México. Syst. Bot. Monogr. 25: 1-522.

" el símbolo "pf" se refiere al herbario del autor. 